\title{
Anesthetic Management of Pheochromocytoma in Pediatric Patient-Case Report
}

\author{
Lam Wai Teng, Siu Man Kit, Chan Si Wai, Leong Fai \\ Department of Anesthesiology, Centro Hospitalar Conde de São Januário, Macao Special Administrative Region, China \\ Email: lamwaiteng2@gmail.com
}

How to cite this paper: Teng, L.W., Kit, S.M., Wai, C.S. and Fai, L. (2021) Anesthetic Management of Pheochromocytoma in Pediatric Patient-Case Report. Open Journal of Anesthesiology, 11, 175-183. https://doi.org/10.4236/ojanes.2021.116017

Received: May 2, 2021

Accepted: June 18, 2021

Published: June 21, 2021

Copyright $\odot 2021$ by author(s) and Scientific Research Publishing Inc. This work is licensed under the Creative Commons Attribution International License (CC BY 4.0).

http://creativecommons.org/licenses/by/4.0/

\begin{abstract}
Background: Pediatric pheochromocytoma is very rare, accounting for only about $1 \%$ of pediatric hypertension. Case Presentation: We presented a case of pediatric pheochromocytoma in a 12-year-old girl undergoing laparoscopic adrenalectomy, with the aim of highlighting an anesthetic challenge. Conclusion: Preoperative screening of hereditary conditions, investigations for end-organ dysfunction, preoperative blood pressure optimization, intensive intraoperative hemodynamic management and good communication with surgeons were the cornerstones for this successful surgery.
\end{abstract}

\section{Keywords}

Anesthesia, Hemodynamic, Pediatrics, Pheochromocytoma

\section{Introduction}

Pheochromocytoma is a rare disease in childhood. Tumors originating from adrenal medulla, arising from chromaffin cells and secreting catecholamines are termed pheochromocytoma. Pheochromocytoma occurs with a frequency of 0.3 cases per million per year and only in about $1 \%$ of the hypertensive pediatric population [1]. It prevails mostly among children and adolescents 6 and 14 years of age [2]. Compared to adults, it is commonly associated with genetic syndromes or familial diseases such as neurofibromatosis, von Hippel-Lindau disease and multiple endocrine neoplasia syndromes (MENII A and B). Diagnosis is usually confirmed by raised urinary catecholamine levels and their metabolites. Tumors are localized by CT scan or MRI. Primary preoperative goals are pharmacological control of adverse effects of circulatory catecholamine, restoration of blood volume, and adequate control of blood pressure, heart rate and arrhythmias. Anesthetic management goals mainly consist of avoiding drugs 
which produce a catecholamine surge, provide optimal surgical conditions and suppressing responses to endotracheal intubation, surgical stimulation, tumor handling and devascularization, and maintaining cardiovascular stability with short-acting drugs, as well as normovolemia and hemodynamics after tumor resection [3]. Drugs causing histamine release are to be avoided, such as atracurium, morphine, suxamethonium (which produces a catecholamine surge by muscle fasciculation), metoclopramide, and ephedrine [4]. Vasoactive agents for hypertensive crisis and hypotensive episodes are essential. Supraventricular tachycardia is most common during surgery: intravenous lidocaine, beta blockade with esmolol, or treatment with amiodarone may be necessary [5]. Post-operative concerns include maintaining optimal blood pressure, as elevated catecholamine levels persist for 7 to 10 days even after adrenalectomy, hypoglycemia and there is a risk of acute postoperative adrenal insufficiency [4]. This case report summarizes the perioperative anesthesia management of adrenal pheochromocytoma in a 12-year-old girl, in hope of sharing information about ways to reduce perioperative risks for similar cases.

\section{Case Presentation}

A 12-year-old girl complaining of a paroxysmal headache (located in the bilateral temporal region) for two weeks, along with dizziness and sweating was admitted to our hospital.

She did not present with fever, chest pain, blurry vision, abdomen pain, nausea or vomiting, but elevated blood pressure was also noted: BP 150-180/110-125 mmHg, HR 110 - $120 \mathrm{bpm}$. She had no documented hypertension family history nor hereditary disease nor malignancy (including, thyroid tumor, neuroma or insulinoma, MEN syndrome, Marfan syndrome, vonHippel-Lindau syndrome). Physical examinations revealed hypertension and tachycardia: BP 150/102 mmHg, HR 122/min, with a body weight of $44 \mathrm{~kg}$ anda height of $166 \mathrm{~cm}$. No marfanoid or cushingoid characteristics, or visual disturbances were reported. Her bilateral lungs were clear to auscultation, Heart murmurs were absent. Her extremities were freely mobile, without edema. Further assessment found that urinaryvanillylmandelic acid (VMA), metanephrines and catecholamines (as shown in Table 1) were elevated over a 24 -houor period. Yet, serum cortisol, parathyroid hormone, aldosterone, and electrolytes were within normal limits, and her liver and renal functions were normal (as shown in Table 2). Subsequent CT scan showed a left adrenal mass (about $5 \times 4.2 \times 4.1 \mathrm{~cm}$ ), heterogeneous enhancement, and suspected pheochromocytoma (as shown in Figure 1(a) and Figure 1(b)). An 18F-FDG PET scan revealed no metastasis. A transthoracic cardiac echogram revealed left ventricle mild hypertrophy, trace mitral valve and tricuspid valve regurgitation, normal aortic valves and normal heart function, left ventricular ejection fraction (LVEF) 65\%. 24-hour Holter monitoring showed no abnormalities, without premature ventricular contractions. Following brain MRI, hypertensive changes were suspected. Brain MRA and MRV were unremarkable. 
Table 1. 24-hour urine vanillylmandelic acid (VMA), metanephrines and catecholamines.

\begin{tabular}{|c|c|c|c|}
\hline $\begin{array}{l}24 \text { hours urine } \\
\text { vanillylmandelic acid }\end{array}$ & $\begin{array}{l}\text { Vanillylmandelic } \\
\text { acid }\end{array}$ & $37.84 \mathrm{mg} / 24$ hours & $\begin{array}{l}\text { Normal range: } 0 \text { - } 13.6 \\
\mathrm{mg} / 24 \text { hours }\end{array}$ \\
\hline \multirow{2}{*}{$\begin{array}{l}24 \text { hours urine } \\
\text { catecholamines }\end{array}$} & Noradrenaline & $2329 \mathrm{mcg} / 24$ hours & $\begin{array}{l}\text { Normal range: } 15 \text { - } 80 \\
\mathrm{mcg} / 24 \text { hours }\end{array}$ \\
\hline & Dopamine & $414 \mathrm{mcg} / 24$ hours & $\begin{array}{l}\text { Normal range: } 65 \text { - } 400 \\
\mathrm{mcg} / 24 \text { hours }\end{array}$ \\
\hline \multirow{2}{*}{$\begin{array}{l}24 \text { hours urine } \\
\text { metanephrines }\end{array}$} & Normetanephrine & $14300 \mathrm{mcg} / 24$ hours & $\begin{array}{l}\text { Normal range: } 55 \text { - } 277 \\
\mathrm{mcg} / 24 \text { hours }\end{array}$ \\
\hline & Metanephrine & $14404 \mathrm{mcg} / 24$ hours & $\begin{array}{l}\text { Normal range: } \\
107-394 / 24 \text { hours }\end{array}$ \\
\hline
\end{tabular}

Table 2. Laboratory test at preoperative and postoperative period.

\begin{tabular}{|c|c|c|c|c|}
\hline & Unit & $\begin{array}{l}\text { Reference } \\
\text { Range }\end{array}$ & $\begin{array}{c}2021 / 03 / 08 \\
\text { (Pre-Operation) }\end{array}$ & $\begin{array}{c}2021 / 03 / 11 \\
\text { (Postoperative Day 2) }\end{array}$ \\
\hline Urea & $\mathrm{mmol} / \mathrm{L}$ & $1.8-6.4$ & 4.7 & 2.3 \\
\hline Creatinine & umol/L & $39-60$ & 50 & 44 \\
\hline Glucose & $\mathrm{mmol} / \mathrm{L}$ & $3.33-5.55$ & 5.15 & 6.5 \\
\hline Sodium & $\mathrm{mmol} / \mathrm{L}$ & $136-145$ & 140 & 137 \\
\hline Potassium & $\mathrm{mmol} / \mathrm{L}$ & $3.5-5.1$ & 3.5 & 4.2 \\
\hline Chloride & $\mathrm{mmol} / \mathrm{L}$ & $98-107$ & 106 & 104 \\
\hline Calcium & $\mathrm{mmol} / \mathrm{L}$ & $2.20-2.70$ & 2.34 & 2.26 \\
\hline Phosphorus & $\mathrm{mmol} / \mathrm{L}$ & $1.05-1.85$ & 1.44 & 1.05 \\
\hline Total Bilirubin & umol/L & $0-15$ & 5 & - \\
\hline $\begin{array}{c}\text { Aspart. } \\
\text { Aminotransferase (AST) }\end{array}$ & $\mathrm{U} / \mathrm{L}$ & $\leq 32$ & 16 & 38 \\
\hline $\begin{array}{c}\text { Alanine } \\
\text { Aminotransferase (ALT) }\end{array}$ & $\mathrm{U} / \mathrm{L}$ & $\leq 33$ & 12 & 32 \\
\hline $\mathrm{Hb}$ & $\mathrm{g} / \mathrm{dL}$ & $13.5-17.0$ & 12.2 & 12 \\
\hline Hct & $\%$ & $41.0-53.0$ & 37.3 & 36.5 \\
\hline WBC & $\times 10^{9} / \mathrm{L}$ & $4.3-10.0$ & 13.3 & 13.3 \\
\hline Platelets & $\times 10^{9} / \mathrm{L}$ & $100-400$ & 218 & 204 \\
\hline
\end{tabular}




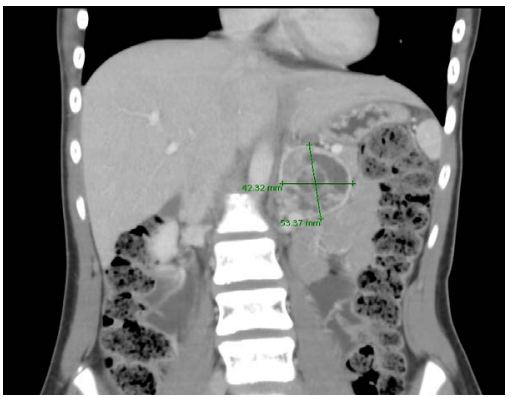

(a)

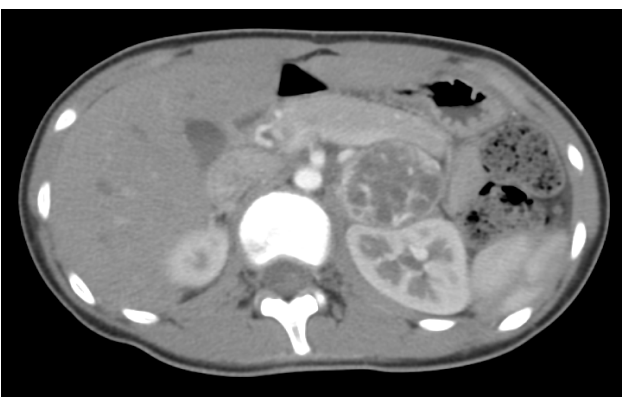

(b)

Figure 1. CT scans showing a left adrenal mass (about $5 \times 4.2 \times 4.1 \mathrm{~cm}$ ), heterogeneousenhancement, and suspected pheochromocytoma.

Under the impression of pheochromocytoma, prazosin $4 \mathrm{mg}$ per oral every 6 hours, metoprolol $25 \mathrm{mg}$ per oral every 12 hours were initiated four weeks prior to surgery. She was advised to start a diet higher in sodium content. Her blood pressure and heart rate were controlled within optimal range (BP 90 - 110/60 -70 $\mathrm{mmHg}$, HR 60 - 80/min). After consultation with the urology department, a laparoscopic adrenalectomy was scheduled. Upon assessment by anesthesiologists, the patient was classed as ASA PS grade II, but due to high perioperative risks, a multi-disciplinary team meeting was organized.

A day before operation, a central line into the right internal jugular vein, and a PICC were inserted. On the day of operation, before induction of anesthesia, an arterial catheter was inserted; defibrillation pads were placed at anterior and posterior positions. Medical devices were prepared to closely monitor the patient's ongoing condition, including a pulse oximeter, an ECG, a urinary catheter, a temperature probe, a capnogram for end tidal carbon dioxide and central venous pressure. For induction, intravenous midazolam $2 \mathrm{mg}$, lidocaine $50 \mathrm{mg}$, fentanyl $0.1 \mathrm{mg}$, propofol $100 \mathrm{mg}$, and rocuronium $40 \mathrm{mg}$ were used. After 5 minutes, intubation was performed under video laryngoscopy. An endotracheal tube of internal diameter $6.5 \mathrm{~mm}$ with cuff was placed. After its correct placement was confirmed by capnography, controlled ventilation was started. No fluctuation of blood pressure and heart rate was noticed during induction and intubation. Anesthesia was maintained with remifentanil $0.1-0.2 \mathrm{mcg} / \mathrm{kg} / \mathrm{min}$, sevoflurane and a mixture of oxygen with air at MAC 1.3 and intermittent bolus of rocuronium. The patient was moved from dorsal to the right oblique position. A laparoscopic left partial adrenalectomy was performed, details were as follows, three ports of $11 \mathrm{~cm}$ were inserted through transperitoneal cavity, followed by lysis of descending colon. The left kidney and left adrenal region were explored. A huge mass about $6 \mathrm{~cm}$ was found at the suprarenal region with many accessory vessels at the tumor. The mass was isolated with harmonic scalpel and clips. The left adrenal gland was mixed with the tumor. A left partial adrenalectomy, along with excision of the suspected pheochromocytoma, was performed, thus completely removing the tumor (as shown in Figure 2). The surgical procedure lasted for two hours. Total fluid input was $1000 \mathrm{ml}$ crystalloid, urine output was 


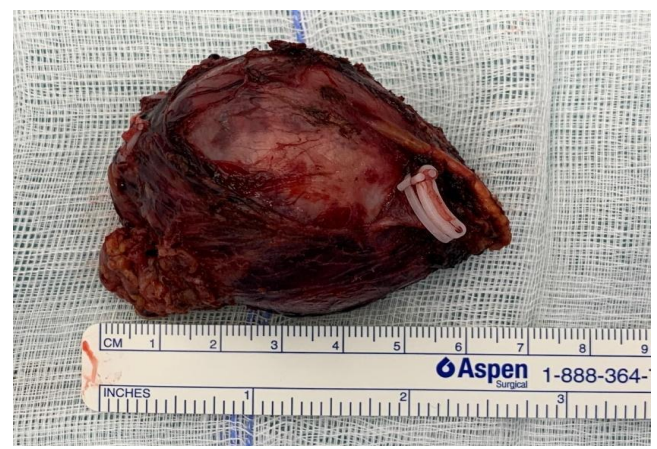

Figure 2. Completely resected tumor.

$400 \mathrm{ml}$ ( $4.5 \mathrm{ml} / \mathrm{kg} /$ hour), estimated intraoperative bleeding was $100 \mathrm{ml}$; no blood products were consumed; there were no major complications, and blood glucose was within a normal range. We made sure that communication between anesthetists and surgeons were effective, so that all of us were clear about the patient's vital signs and each important surgical step throughout the procedure. During skin incision, initial arterial blood pressure was around 140 - 160/70 - 80 $\mathrm{mmHg}$, heart rate $100-110 / \mathrm{min}$, hypertension was controlled with sodium nitroprusside infusion (beginning with $0.3 \mathrm{mcg} / \mathrm{kg} / \mathrm{min}$, titrated accordingly). During insufflation of carbon dioxide and creation of pneumoperitoneum, target pressure was set at $12 \mathrm{mmHg}$, and when the adrenal gland was manipulated, dramatic changes in blood pressure amounting to sudden hypertension (with BP reaching as high as $150-180 / 100-110 \mathrm{mmHg}$ ) and episodes of non-sustained ventricular tachycardia were observed. Hypertension was controlled with additional boluses of esmolol $10 \mathrm{mg}$, on top of increasing nitroprusside infusion. Non-sustained ventricular tachycardia was self limited after the use of intravenous lidocaine $50 \mathrm{mg}$. Whenever veins supplying the adrenal gland were clamped, hypotension was noted (with BP reachingas low as $50-60 / 30-40 \mathrm{mmHg}$ ). Blood pressure was optimized with boluses of crystalloid to maintain CVP at 12 $15 \mathrm{mmHg}$; push doses of phenylephrine $100 \mathrm{mcg}$ and all antihypertensive agents were discontinued. However, hypotension was sustained after the removal of adrenal gland and noradrenaline infusion was initiated. Hydrocortisone was administered. At the end of operation, spontaneous ventilation was ensured, tidal volume was $5 \mathrm{ml} / \mathrm{kg}$; and the patient could open eyes to call. Emergence was smooth, and she was extubated at the end of operation. The patient was conscious, cooperative, without gross neurological deficits. Noradrenaline was tapered gradually and discontinued at postoperative day 2. Blood tests including renal, liver function and electrolytes were unremarkable (as shown in Table 2). With paracetamol given regularly, visual analogue scale (VAS) was 3/10 and subsided afterwards, the patient was satisfied. Her blood pressure was between 110 - 120/60 - $70 \mathrm{mmHg}$, HR 70 - 90/min, without antihypertensive medication. The postoperative course was uneventful. She was discharged home on postoperative day 10. Pathological report revealed that the specimen weighted 50 grams, measuring $6 \times 4.5 \times 3.6 \mathrm{~cm}$; it was consistent with pheochromocytoma. 
Genetic analysis found one pathogenic variant identified in von Hipple-Lindau syndrome.

\section{Discussion}

Compared to adults, pheochromocytoma in children is often associated with genetic syndromes or familial diseases. Hence, in our case, the patient was screened for genetic traits, which eventually suggested von Hippel-Lindau syndrome (VHL). We also requested the patient's sibling for further investigation and this case will be followed up regularly in future.

It has been reported that children and adolescents are at a higher risk than adults for malignant disease when pheochromocytoma occurs and that $50 \%$ of children with pheochromocytoma have malignant or metastatic disease [6]. Increased risk factors for malignancy include paraganglioma, and tumor size larger than $6 \mathrm{~cm}$, risk for patients with VHL syndrome or VHL pathogenic variants is intermediate about 10\% [6]. A PET CT evaluation was performed to exclude the possibility of metastasis and other extra adrenal tumors.

Excess catecholamine can cause pathophysiological changes in cardiovascular and other systems. Symptomatic patients may develop catecholamine cardiomyopathy [6]; echocardiogram was performed to rule out end-organ dysfunction.

Preoperative medical treatment is essential to preventing catecholamine-induced hypertensive crisis and malignant arrhythmias [7]. In contrast, patients are also at risk of postoperative hypotension due to chronic vasoconstriction and volume contraction. In our case, the blood pressure was controlled for four weeks instead of just two weeks according to most recommendations, with alpha followed by beta blocking agent prior to surgery. The patient's blood pressure eventually reached a level optimal for her age, with no orthostatic hypotension or arrhythmia. We also recommended liberal salt intake such that it may cause intravascular volume expansion. We believed that in our case, the intraoperative hemodynamic alterations did not lead to the diagnosis of pheochromocytoma crisis, which is defined as severe hypertension or hypotension resulting in end-organ damage. This can be explained by our prolonged preoperative management.

To prevent our pediatric patient from prolonged anesthesia and anxiety while inside the operation room, we chose to insert the central lines in the pediatric ward a day before operation and an arterial catheter prior to induction.

The first part of this surgery (which gave rise to a surge in catecholamine) included endotracheal intubation, insufflation of abdomen with carbon dioxide for laparoscopy, tumormanipulation and the isolation of vascular supply before clamping of the adrenal vein. It is featured by periods of severe hypertension and arrhythmias [8]. The second part of the surgery commenced after the adrenal vein is clamped. Obvious hypotension can occur due to the sudden drop in endogenous catecholamine levels, chronic downregulation of alpha-adrenergic re- 
ceptors, presence of alpha-blocking medication and intravascular volume depletion [8]. Vasopressor support is often necessary. Our case bears similarities to the situations mentioned above. Since hemodynamic fluctuations and malignant arrhythmia were expected, we prepared one central line and another PICC, allowing us to infuse multiple antihypertensive agents, vasoactive drugs, or volume restoration and simultaneously continue recording the real time central venous pressure. For vasopressors, we prepared noradrenaline infusion, vasopressin infusion and push doses of phenylephrine; for hypotensive agentswe prepared nitroprusside infusion and push doses of esmolol; and for arrhythmia, we prepared lidocaine, amiodarone. Defibrillation pads were placed anteriorly and posteriorly before induction in order to provide prompt treatment while the patient was covered with drapes. We found out it was easier to control the hemodynamics when our surgeons were informing us ahead of time of what they would do next. To control hypertensive episodes during operation, infusion of non-selective alpha blocker such as phentolamine was recommended [9] [10], yet we do not have this medication in our hospital, and nitroprusside infusion was chosen instead. However, the blood pressure control was not ideal, perhaps due to dose- or timing-related issue. Thus, we initiated boluses of esmolol. We believed that as alpha blocker had been used for an adequate duration in our case and its effect had been established, thus the catastrophic hypertensive crisis owing to unopposed alpha receptor stimulation was not seen even when esmolol was used without any alpha blockers.

Lastly, we did not choose an epidural general anesthesia method and remifentanil infusion was administered. The adrenal glands are innervated by sympathetic nerves from T5 to T12. Epidural anesthesia would create sympathetic blockade, and provide optimal analgesia, thus reducing catecholamine release. This has been described in spontaneous vaginal delivery [11]. However, epidural anesthesia in laparoscopy may not be appropriate, as it only provides a segmental block, which would not give an adequate pain relief during gas insufflation to create pneumoperitoneum. Additionally, it was reported that the combined epidural-general anesthesia during laparoscopy was not effective in attenuating hypertensive responses, and could have exacerbated intraoperative hypotension [12].

\section{Conclusion}

The management of anesthesia in pheochromocytoma is very challenging because of excessive and depleted catecholamines in the perioperative period. A thorough preoperative evaluation, aggressive optimization of hemodynamics during intraoperation and close monitoring of any complications during the postoperative period are the key to success.

\section{Conflicts of Interest}

The authors declare no conflicts of interest regarding the publication of this paper. 


\section{References}

[1] Sadiqa, E. and Daniel, M.F. and Alison, G. (2011) Pheochromocytoma. Pediatrics in Review, 32, 308-310. https://doi.org/10.1542/pir.32-7-308

[2] Pamporaki, C., Hamplova, B., Peitzsch, M., Prejbisz, A., Beuschlein, F., Timmers, H.J.L.M., Fassnacht, M., Klink, B., Lodish, M., Stratakis, C.A., Huebner, A., Fliedner, S., Robledo, M., Sinnott, R.O., Januszewicz, A., Pacak, K. and Eisenhofer, G. (2017) Characteristics of Pediatric vs Adult Pheochromocytomas and Paragangliomas. The Journal of Clinical Endocrinology and Metabolism, 102, 1122-1132.

[3] Barak, C., Aviel, S., Sorina, O., Idit, M. and Bruno, R. (2011) Case Scenario: Metastatic Pediatric Paraganglioma Presenting during the Course of an Elective Surgery. Anesthesiology, 115, 408-413. https://doi.org/10.1097/ALN.0b013e318222ac2a

[4] David, C. and Stephen, B. (2016) Perioperative Care of Phaeochromocytoma. BJA Education, 16, 153-158. https://doi.org/10.1093/bjaed/mkv033

[5] Strauss, L. (2018) A Practical Approach to Children with Phaeochromocytomas and Paragangliomas. Southern African Journal of Anaesthesia and Analgesia, 24, S43-S48.

[6] Pham, T.H., Moir, C., Thompson, G.B., Zarroug, A.E., Hamner, C.E., Farley, D., van Heerden, J., Lteif, A.N. and Young, W.F. (2006) Pheochromocytoma and Paraganglioma in Children: A Review of Medical and Surgical Management at a Tertiary Care Center. Pediatrics, 118, 1109-1117. https://doi.org/10.1542/peds.2005-2299

[7] Park, J.H., Kim, K.S., Sul, J.-Y., Shin, S.K., Kim, J.H., Lee, J.H., Choi, S.W., Jeong, J.-O. and Seong, I.-W. (2011) Prevalence and Patterns of Left Ventricular Dysfunction in Patients with Pheochromocytoma. Journal of Cardiovascular Ultrasound, 19, 76-82. https://doi.org/10.4250/jcu.2011.19.2.76

[8] Joris, J.L., Hamoir, E.E., Hartstein, G.M., Meurisse, M.R., Hubert, B.M., Charlier, C.J. and Lamy, M.L. (1999) Hemodynamic Changes and Catecholamine Release during Laparoscopic Adrenalectomy for Pheochromocytoma. Anesthesia \& Analgesia, 88, 16-21. https://doi.org/10.1097/00000539-199901000-00004

[9] Lenders, J.W.M., Duh, Q.Y., Eisenhofer, G., Gimenez-Roqueplo, A.-P., Grebe, S.K.G., Murad, M.H., Naruse, M., Pacak, K. and Young, W.F. (2014) Pheochromocytoma and Paraganglioma: An Endocrine Society Clinical Practice Guideline. The Journal of Clinical Endocrinology and Metabolism, 99, 1915-1942. https://doi.org/10.1210/jc.2014-1498

[10] Wesley, D.M., Bryan, J.T., William, E.C. and Rose, C.C. (2011) Phentolamine Continuous Infusion in a Patient with Pheochromocytoma. American Journal of Health-System Pharmacy, 68, 130-134. https://doi.org/10.2146/ajhp090619

[11] Strachan, A.N., Claydon, P. and Caunt, J.A. (2000) Phaeochromocytoma Diagnosed during Labour. British Journal of Anaesthesia, 85, 635-657.

https://doi.org/10.1093/bja/85.4.635

[12] Soeun, J., Cho, A.-R., Ri, H.-S., Lee, H.-J., Hong, J.-M., Lee, D., Park, E.J., Kim, J. and Kang, C. (2020) The Effect of Combined Epidural-General Anesthesia on Hemodynamic Instability during Pheochromocytoma and Paraganglioma Surgery: A Multicenter Retrospective Cohort Study. International Journal of Medical Sciences, 17, 1956-1963. https://doi.org/10.7150/ijms.47299 


\section{Abbreviations}

ASA PS: American Society of Anesthesiologists Physical Status

BP: Blood Pressure

CT: Computerized Tomography

CVP: Central Venous Pressure

HR: Heart Rate

MAC: Minimum Alveolar Concentration

MRA: Magnetic Resonance Angiogram

MRI: Magnetic Resonance Imaging

MRV: Magnetic Resonance Venography

MEN: Multiple Endocrine Neoplasia

PICC: Peripherally Inserted Central Catheter

18F-FDG PET: 18-Fluorine-Fluorodeoxyglucose Positron-Emission-Tomography 